\title{
Super Why! to the Rescue: Can Preschoolers Learn Early Literacy Skills from Educational Television?
}

\author{
Deborah L. Linebarger \\ University of Iowa \\ United States of America
}

\begin{abstract}
Decades of research support our understanding that, created with the intent to teach, educational television can go far toward supporting a child's academic and prosocial development. The purpose of this study was to test whether Super Why!, an educational TV program that models key early literacy skills, could teach young children early literacy skills. In total, 171 preschool children were randomly assigned to watch Super Why! or an educational science program. Children viewed 20 episodes of their assigned program twice. Children's early literacy skills were evaluated prior to viewing, after viewing all episodes at least one time, and after viewing all episodes a second time. Children who viewed Super Why! over an 8-week period outperformed their control group peers on nearly all child outcomes. Learning was most pronounced for letter knowledge and phonological and phonemic awareness skills, key early precursors of later conventional reading success.
\end{abstract}

\section{Introduction}

Decades of research support our understanding that, created with the intent to teach, educational television can go far toward supporting a child's academic and prosocial development [1, 2], particularly a child living in poverty who may lack access to other available educational and cognitive resources. Since the creation of the foundational program Sesame Street in the late 1960s, television shows continue to be developed, tested, revised and improved in order to extend the role of broadcast television as an in-home instructor.

The most recent addition to television's educational landscape is a program called Super Why! This series is aimed at viewers 3 to 6 years of age and focuses on the development of critical early literacy skills including alphabet and word family knowledge, spelling, comprehension, vocabulary and story structure. What makes this program unique is its incorporation of interactive features similar to those found to be successful in engaging viewers in the program Blue's Clues [3]. The on-screen "teachers" in Super Why! speak to and ask questions of at-home viewers in order to connect with them and direct their learning. By using relatable characters, familiar stories, interactive games, humor, and a sense of adventure in each story, Super Why! encourages kids to approach the literacy curriculum in an engaging way. Each episode of Super Why! exposes viewers to the elements of literacy that are fundamental to later, successful reading: stories, characters, language development, vocabulary, letter identification, letter sounds, rhyming, word families, comprehension, and text. The foundation of the curriculum is that, through interactivity and practice, preschoolers will both learn to read and love to read.

\section{Study Purpose}

This study was undertaken with the purpose of determining the ability of Super Why! to effectively help children acquire key early literacy skills (i.e., language development, letter knowledge, phonological and phonemic awareness, and print conventions). Two questions were asked: 1) did the program produce positive changes in the acquisition of these early literacy skills and 2) how many episodes did children need to view to demonstrate meaningful changes across these skills? An experimental research design was used to answer these questions. Children were randomly assigned to one of two groups: a Super Why! viewing group and a control group (i.e., viewed a science-oriented program). This approach allowed us to answer basic questions about the program's ability to produce growth in early literacy skills over time.

\section{Method}

\subsection{Participants}

A total of 171 children and families (Mean age = 58.79 months, $\mathrm{SD}=7.62 ; 56.1 \%$ boys) participated in this research project. Children and families were recruited from preschools located in a large Pacific Northwestern city. After receiving approval from the Institutional Review Board at the University of Pennsylvania, children with parental consent participated in the assessments and viewing sessions 
in their homes $(\mathrm{n}=133)$ or schools $(\mathrm{n}=38)$. The children and families in this study ranged from lower socioeconomic status (SES) to higher SES. In this study, SES categories were formed using a metric derived from combined family income and family size. This metric, called an income-to-needs ratio, was created by dividing family income by the US poverty threshold for a particular family's size (e.g., the 2008 poverty threshold for a family of 4 was $\$ 21,200$ ). Families with income-to-needs ratios below 2.0 were classified as low-income because they were living in or near poverty (i.e. LOW); ratios between 2.0 and 3.0 were classified as lower middleclass/working-class (i.e., WC); and ratios above 3.0 were classified as middle to upper SES (i.e., MID).

\subsection{Design}

A 2 (viewing group) x 3 (SES group) experimental ANCOVA design was used. Random assignment to viewing group was completed at the individual level.

\subsection{Measures}

Measures were selected to assess targeted skills demonstrated throughout Super Why! and to reflect the key early literacy skills as described by Neuman and Roskos [4]. These skills were language development, letter knowledge, phonological and phonemic awareness, and print conventions.

3.3.1. Child and Family Characteristics. Questionnaires were hand delivered to parents during data collection sessions with their children or were delivered to parents through the daycare center attended by the child. Parents reported their home media environment; media use; and family demographic information.

3.3.2. Child Viewing Logs. Families were first randomly assigned to a viewing group. As part of their initial enrollment into the study, parents were told that they would need to have their child watch a new episode each day for a total of 20 days. During that time, parents kept detailed viewing logs. Once the first set of 20 episodes was viewed, our research team collected the round one diaries, delivered a new diary, and asked the families to view each of the first 20 episodes a second time. Diaries contained spaces to record which episode a child watched on a given day, how many times they watched that episode, who was present during the viewing, and what the child and/or parent did while viewing a particular episode. In addition to the assigned episode, many families allowed their children to watch episodes previously viewed.
3.3.3. Child Outcomes. Generalized vocabulary knowledge was evaluated using the Picture Naming Task, a tool that measured children's expressive language knowledge (PNT) [5]. The PNT is used to track preschoolers' vocabulary acquisition on a regular basis over time. Children were presented with images of objects familiar to them one at a time and asked to name the pictures as fast as possible for one minute. Categories of objects used included animals, food, people, household objects, games and sports materials, vehicles, tools, and clothing. Psychometric properties for this measure were adequate. Specifically, alternate forms reliability ranged between .44 and .78 while test-retest reliability over a two-week period was .69. Concurrent validity estimates with the Peabody Picture Vocabulary Test - 3rd Edition and with the Preschool Language Scale -3 were adequate, .53 to .79. The PNT was also sensitive to developmental status and growth over time. Children identified 21.4 pictures at the pretest $(\mathrm{SD}=6.7)$. Benchmarking norms were provided by the authors: scores at 59 months averaged 16.97 for typically developing children; 16.51 for children from low income backgrounds; and 14.13 for children with identified disabilities [5]. PALS PreK - Alphabet Knowledge. Three different tasks tapped into various components of letter knowledge: 1) identification of the 26 Upper Case letters; 2) identification of the 26 Lower Case letters; and 3) identification of the sounds associated with 23 letters and 3 digraphs. Children are first presented all 26 Upper Case letters in a random order. To be eligible to proceed to the second task, identification of all 26 Lower Case letters, the child must correctly identify 16 Upper Case letters. To be eligible to proceed from Lower Case letters to Letter Sounds, the child must correctly identify 9 Lower Case letters. Psychometrics are adequate with reported reliabilities ranging from .74 to .94 . With this task, we derived two scores: the number of letters or sounds a child could correctly identify and the number of seconds it took to identify one letter or sound (i.e., fluency score). PALS-PreK Rhyme Awareness. Rhyme awareness is one aspect of beginning phonological awareness, or an ability to attend to and manipulate sound units within spoken words [6]. Children were asked to identify a picture name that rhymed with a target word. Acceptable responses could be verbal or nonverbal (e.g., pointing to the correct picture). This PALS PreK subtest is designed to provide an appropriate level of difficulty for preschool children (neither too difficult nor too easy) and has demonstrated a strong predictive relationship with later reading achievement. Children were given a score of (1) for every correct answer provided and a (0) for every incorrect answer provided, with a maximum score of 10 at each testing point. Children correctly identified 7.5 rhymes at the pretest $(\mathrm{SD}=2.2$ ). The PALS PreK 
manual reports a Spring Developmental Range (similar to a benchmark) between 5 and 7 rhymes. Get Ready to Read! Screener. This screener, consisting of 20 items, assessed print knowledge (i.e., knowledge of the letters of the alphabet); book knowledge (recognition of how books work including the difference between words and images); phonological awareness (i.e., understanding that spoken words are composed of individual sounds); phonics (i.e., recognition of the sounds letters make); and writing (i.e., understanding how text should look: letters grouped together into words). Each item required the child to select a response from a group of four pictures (or four letters, words, etc.). Example: "These are pictures of a book. Find the one that shows the back of the book." Example: "Find the letter that makes a tuh sound." Example: "Some children wrote their name. Find the one that is written the best." Children were given a score of a (1) for every correct answer provided and a (0) for every incorrect answer provided, with a maximum score of 20 points. The average pretest score was 15.90 (SD = 3.50). Scores greater than 11 are predictive of reading success by 2 nd grade.

\subsection{Analytical Approach}

Four covariates were constructed to extract relevant variance associated with both viewing and outcomes as well as to remove possible effects associated with pre-existing child and family characteristics. A child composite was formed by zscore transforming and summing child's birth order, age, and gender. A family composite was formed by $\mathrm{Z}$-score transforming and then summing parental age, parental years of education, number of persons living in the home, and yearly income1. Finally, a composite representing the child's initial ability was constructed. All pre-test scores were z-score transformed and summed minus the measure evaluated in a particular analysis (e.g., for the PALS Upper Case measure, the composite consisted of PALS Lower Case, PALS Letter Sounds, PALS Rhyme Awareness, Picture Naming, and Get Ready to Read).

Question 1 regarding the effectiveness of viewing Super Why! on early literacy skills was tested using a repeated-measures Analysis of Covariance (ANCOVA). This is a procedure that can be used to statistically control for initial group differences (as measured by the child composite, the family composite, and the child's pre-test literacy ability) when evaluating control/viewing effects on outcome measures. Two different models were used to evaluate each outcome. The first set of analyses involved testing the effects of viewing group only. That is, did children who watched Super Why! outperform children who watched an alternate program on all outcomes? Next, the moderating role of family socioeconomic status (SES) was examined. In these models, both Viewing Group and Family SES were included as factors. Family SES included 3 levels (i.e., low, working-class, middle SES). When multiple tests were conducted for each set of outcomes, Bonferroni adjustments of the alpha level were made to reduce Type 1 error rates (i.e., finding a significant difference when one does not exist). For these analyses, only significant effects associated with Group are reported in the text (i.e., Group; Wave by Group). Along with the statistical significance tests, effect sizes were also reported. Finally, when the sphericity assumption was violated, we used a Huynh-Feldt correction to adjust the degrees of freedom.

Question 2 regarding how many episodes of Super Why! were needed to produce meaningful change across the early literacy skills tested was examined (referred to as Dose Analysis). For these analyses, exposure was defined as the total number of episodes each child viewed over the duration of the project. Using exposure as the independent variable, three different regression models were fit to each early literacy outcome to determine whether exposure produced a linear effect, a quadratic effect, or a cubic effect on the outcome. The best fit to the data was determined by the highest-order exposure variable that resulted in a significant change in the $R^{2}$ value; that is, if the amount of variance accounted for significantly increased with the inclusion of a squared or cubic exposure variable, then that model was considered to fit the outcome data best. Linear models indicate that as exposure increased by one episode, outcome scores increased by one point (or second in the case of the fluency measures). Quadratic functions indicate that, as the number of episodes viewed increased, the outcome scores increased. However, the actual change between each additional episode viewed was slowing down (e.g., at episode 1 , the change might be 0.04 while at episode 16 , the change might be as small as 0.008). This declining rate of change is provided in the column identified as

"Change per Episode Viewed" in Table X. At a particular number of episodes, children's outcome scores would begin to get smaller. The point at which this occurs is provided in the last cell of the table row and is reported using the following text: The maximum score is associated with 26.0 episodes and represents a positive change of 1.04. Finally, a cubic function contained curves where outcome totals are accelerating or decelerating as a function of the amount of exposure. For instance, there may be a rather steep acceleration in a skill for children who viewed Super Why between 1 and 30 times followed by a period of no gains or even a slight declines for those who viewed Super Why between 31 and 50 times, followed by another steep acceleration for 
those who viewed Super Why between 51 and 100 times.

\section{Results}

\subsection{Picture Naming Task}

Performance on this task did not differ by viewing group: Super Why! viewers identified 23.11 pictures and Control viewers identified 23.18 pictures, $\mathrm{F}(1$, $166)=0.01$, n.s. Family SES did not moderate the relation between Picture Naming and a child's viewing group.

\subsection{Alphabet Knowledge}

Super Why! viewers at the post-test correctly identified 22.28 Upper Case letters compared with 21.29 Upper Case letters for the Control Group viewers, Upper Case: $\mathrm{F}(1.95,323.40)=4.39, p<$ 0.02 . Overall, $S W$ viewers scored $4.7 \%$ higher than their Control viewing peers and grew $11.5 \%$ from pretest to post-test while Control viewers grew just $5.8 \%$ (Figure 1).

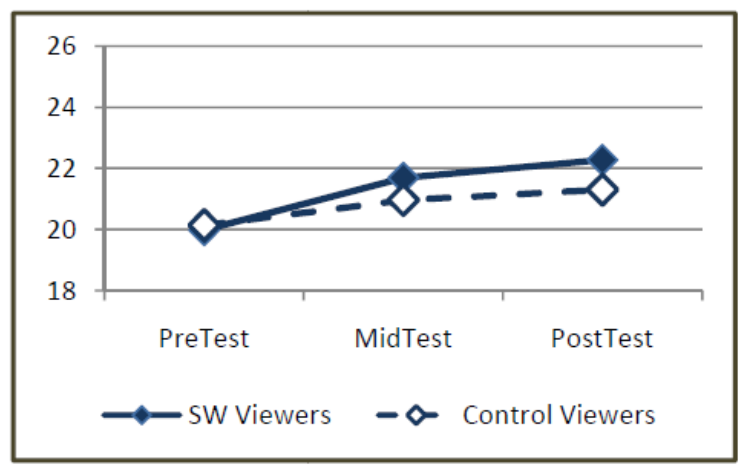

Figure 1. Upper Case Knowledge by Viewing Group

The same pattern for Upper Case letters was also found for Lower Case letters. Super Why! viewers' performance significantly increased over time, resulting in higher scores at both the mid- and the post-test when compared with Control viewers' scores over time, Lower Case: $\mathrm{F}(1.96,325.41)=$ 4.02, $p<0.02$. At the post-test, the Super Why! group correctly identified 17.63 Lower Case letters compared with 15.65 Lower Case letters for the Control Group viewers. Overall, Super Why! viewers scored $12.7 \%$ higher than their Control viewing peers and grew $15.2 \%$ from pretest to post-test while Control viewers grew just $1.6 \%$ (Figure 2).

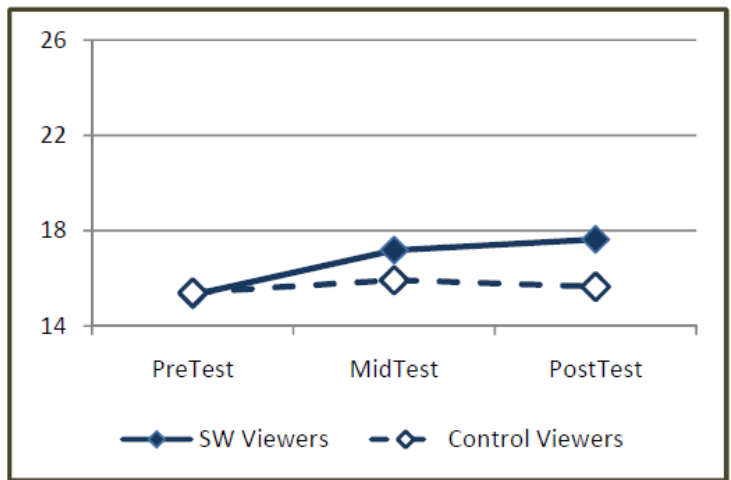

Figure 2. Lower Case Knowledge by Viewing Group

Figure 3. Lower Case Knowledge by Viewing Group Across Time

Fluency was examined by timing the administration of both the Upper Case and Lower Case letter knowledge subscales of the PALS PreK Alphabet Knowledge task. Children in the Super Why! Group identified Upper Case letters more quickly than children in the Control Group: 2.2 seconds per Upper Case letter for $S W$ viewers compared with 2.9 seconds per letter for Control viewers, $\mathrm{F}(1,166)=6.79, p<0.01$. Children in the $S W$ Group identified Lower Case letters more quickly than children in the Control Group: 2.4 seconds per Lower Case letter for $S W$ viewers compared with 3.3 seconds per letter for Control viewers, $\mathrm{F}(1,166)=9.27, p<0.01$. Family SES did not moderate the relation between any alphabet knowledge indicators and viewing group.

\subsection{Rhyming Knowledge}

Children in the Super Why! group identified more rhymes at the post-test compared with Control Group viewers, $\mathrm{F}(1,166)=5.93, p<0.02$. Out of 10 rhymes, $S W$ viewers identified 8.34 at the post-test while Control viewers identified only 7.63 rhymes, a difference of $9.3 \%$. Family SES did moderate the relation between rhyming knowledge and a child's viewing group. There was a 3-way interaction among Group, Family SES, and Wave, F(4, 324) = 3.24, $p<$ 0.05 . $S W$-viewing preschoolers living in Low SES families and in Middle SES families outperformed their Control-viewing peers while $S W$-viewing preschoolers living in Working-Class families scored similarly to their Control-viewing peers (Figure 3). 


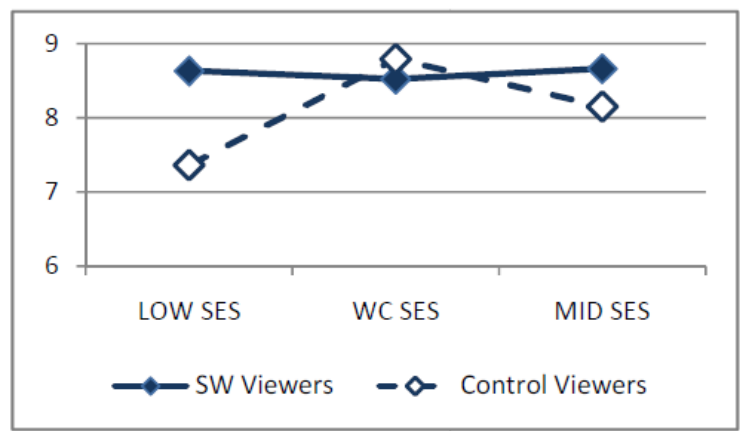

Figure 3. Rhyming Knowledge by Viewing Group and Family SES

\subsection{Letter Sounds Knowledge}

Children in the Super Why! group knew more letter sounds at the post-test when compared with Control Group viewers, $\mathrm{F}(1,166)=4.23, p<0.05$. In addition, the Super Why! viewers' performance significantly increased over time, resulting in higher scores at the mid-test and the post-test when compared with Control viewers' performance over time, $\mathrm{F}(2,331.2)=3.02, p<0.05$. Figure 4 provides the overall letter sounds mean scores as well as the scores across the 3 waves of assessment.

Children in the Super Why! group identified letter sounds more rapidly than children in the Control Group: 4.5 seconds per letter sound for $S W$ viewers compared with 6.6 seconds per sound for Control viewers, $\mathrm{F}(1,166)=6.79, p<0.01$. Family SES did not moderate the relation between letter sounds knowledge and a child's viewing group.

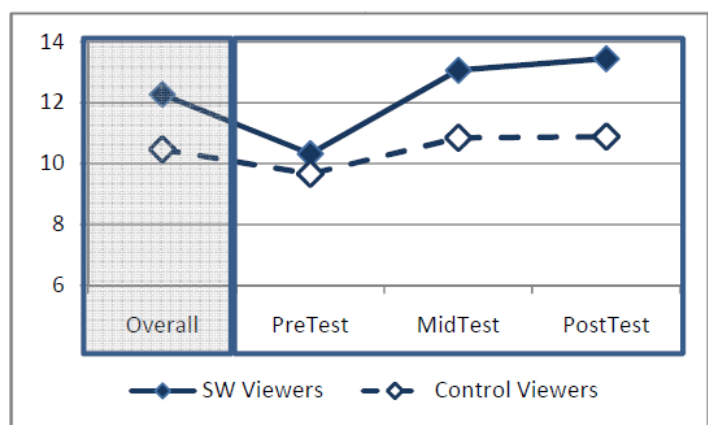

Figure 4. Letter Sounds Knowledge by Viewing Group Overall and by Wave

\subsection{Get Ready to Read! Screener}

Children's print knowledge, emergent writing, and linguistic awareness skills as measured by the Get Ready to Read! screener were significantly higher for Super Why! viewers compared with Control group viewers, a difference of $4.4 \%$ at the post-test, $F(1,166)=5.78, p<.02$. Family SES did not moderate the relation between the Get Ready to Read screener and a child's viewing group (Figure 5).

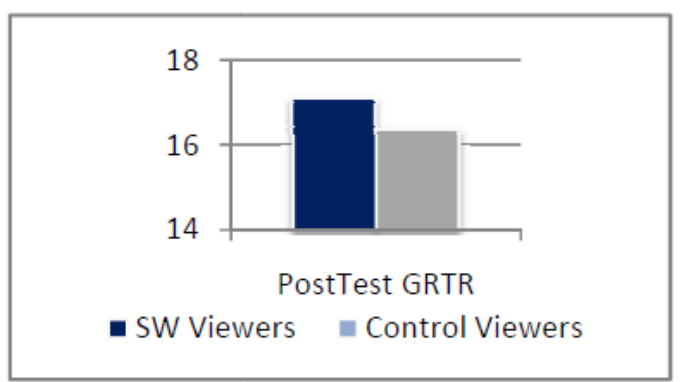

Figure 5. Get Ready to Read! Scores by Viewing Group

\subsection{Dose Analysis}

Children in the Super Why! group watched an average of 38.9 episodes over the course of the viewing phase ( $S D=32.3$ episodes). Outcomes shifted by one point relatively easy; however, the majority of relations between outcomes and exposure were curvilinear (i.e., quadratic functions). Curvilinear relations indicated that as exposure increased initially, outcome scores increased. At a particular point in exposure, the benefits of watching more episodes were not found. That is, the change associated with each additional episode viewed became smaller and smaller. Table $\mathrm{X}$ indicates how much exposure was associated with the maximum change per episode and the maximum outcome score.

\section{Discussion}

The acquisition of early literacy skills occurs within the everyday environments where preschoolers spend their time. Children whose environments are richly filled with language- and literacy-based materials and whose daily interactions with parents, caregivers, siblings and peers are also infused with frequent high-quality language- and literacy-promoting interactions often have little difficulty navigating a path to conventional reading success. In contrast, those children whose daily environments are characterized by few language and literacy materials and impoverished interactions are at a substantial disadvantage. By formal school entry, these children are typically far behind their more advantaged peers. Even at this early age, it is often extremely difficult to catch up without intensive remedial instruction. Even with this remediation, these children will always be at increased risk for reading-specific as well as general academic failure [7-10].

Super Why! provided all children in this study with language- and literacy-learning opportunities that translated into literacy gains across most of the early literacy indicators (i.e., alphabet knowledge, phonological awareness, phonemic awareness, and knowledge of the mechanics of reading). The 
acquisition of these specific skills also contributed to Super Why! viewers' stronger performance on a general early literacy screener. While all $S W$-viewing preschoolers in this study significantly improved their early literacy skills, when there were interactions between viewing group and family SES, children from lower SES families who watched Super Why! always outperformed their control group peers while children whose families were from middle SES backgrounds often already had these skills prior to the intervention. In these cases, both viewing groups performed similarly.

The most impressive set of findings from this study involved children's alphabet knowledge skills. Across the board, Super Why! viewers were able to identify more upper and lower case letters and their corresponding letter sounds. Letter and sound naming skills are foundational skills that represent major landmarks in the acquisition of literacy skills and that are predictive of conventional reading success [11-13].

Watching Super Why! not only improved letter and sound identification but, perhaps more importantly, improved preschoolers' letter and sound naming speed or fluency. Fluencies in letter and sound identification are critical precursors to the acquisition 


\begin{tabular}{|c|c|c|c|c|}
\hline & Model Type & $\begin{array}{c}\text { Change per Episode } \\
\text { Viewed }\end{array}$ & $\begin{array}{l}\text { Episodes Needed for } \\
1 \text { Point Change }\end{array}$ & $\begin{array}{c}\text { Episodes Needed for SD } \\
\text { Change }\end{array}$ \\
\hline \multicolumn{5}{|l|}{ Language Indicators } \\
\hline Picture Naming & \multicolumn{4}{|c|}{ No relation between viewing and outcome } \\
\hline \multicolumn{5}{|l|}{ Alphabet Knowledge } \\
\hline Upper Case Total & Linear & 0.31 & 3.23 episodes & 6.40 letters $\quad 20.7$ episodes \\
\hline Upper Case Fluency & Quadratic & $\begin{array}{l}0.008 \text { ( } 1 \text { episode }) \text { to } 0.005 \\
\text { letters/sec ( } 9.2 \text { episodes })\end{array}$ & 9.2 episodes & $\begin{array}{l}\text { The fastest letter-naming rate is with } 29.3 \text { episodes } \\
\text { (1.4 sec/letter), increasing from there }\end{array}$ \\
\hline Lower Case Total & Linear & 0.40 & 2.50 episodes & 9.70 letters $\quad 24.3$ episodes \\
\hline Lower Case Fluency & Quadratic & $\begin{array}{l}0.012 \text { ( } 1 \text { episode }) \text { to } 0.010 \\
\text { letters/sec ( } 3.8 \text { episodes })\end{array}$ & 3.8 episodes & $\begin{array}{l}\text { The fastest letter-naming rate is with } 25.0 \text { episodes } \\
(1.7 \mathrm{sec} / \text { letter }) \text {, increasing from there }\end{array}$ \\
\hline \multicolumn{5}{|l|}{ Rhyming Knowledge } \\
\hline Rhyming & Linear & 0.10 rhymes (of 10 ) & 10 episodes & 24.0 episodes \\
\hline \multicolumn{5}{|l|}{ Letter Sounds Knowledge } \\
\hline Letter Sounds & Quadratic & $\begin{array}{l}0.276 \text { ( } 1 \text { episode }) \text { to } 0.275 \\
\text { (1.4 episodes })\end{array}$ & 1.4 episodes & \multirow{2}{*}{$\begin{array}{l}\text { The highest letter-sound score is found with } 5.7 \\
\text { episodes ( } 15.7 \text { sounds), dropping from there } \\
\text { The fastest sound rate is with } 25.0 \text { episodes ( } 2.2 \\
\text { sec/sound) dropping from there }\end{array}$} \\
\hline Letter Sounds Fluency & Quadratic & $\begin{array}{l}0.013 \text { ( } 1 \text { episode) to } 0.012(2 \\
\text { episodes })\end{array}$ & $<1$ episode & \\
\hline \multicolumn{5}{|c|}{ Combined Early Literacy Task } \\
\hline Get Ready to Read & Linear & 0.18 points & 5.6 episodes & 13.3 episodes \\
\hline
\end{tabular}


of phonological sensitivity, the alphabetic principle (i.e., letter-sound correspondence), and visual word recognition. Phonological sensitivity refers to the ability to detect and manipulate the sound structure of oral language (includes skills such as rhyming, alliteration, blending, segmenting). As children's skills develop, their ability to discriminate the sounds of speech becomes finer and eventually leads to phonemic sensitivity or the ability to discriminate the smallest units of sounds in words (i.e., phonemes). The largest gains (i.e., effect sizes) across all early literacy skills measured in this study were the effects found for Super Why-viewing preschoolers' letter and sound naming speed (i.e., Cohen's $d$ ranged from 1.51 to 1.94; Cohen [14] reports that effect sizes above 0.80 are large effects). While identifying letters and sounds are important skills, children's speed in doing so is also closely linked to later reading achievement. Faster naming is indicative of greater automaticity (i.e., little processing needs to be devoted to identifying letters or sounds) and ultimately frees up preschoolers' limited cognitive processing skills, making them available for more sophisticated cognitive processing. The likely path of effects proceeds from letter recognition to lettersound knowledge and phonological sensitivity, further discriminations representing phonemic sensitivity that ultimately supports the acquisition of the alphabetic principle and conventional reading and spelling skills [12].

Watching Super Why! resulted in universally large effects on all aspects of letter knowledge ranging from the easiest skill (i.e., Upper Case Letter Identification) to the more complex (i.e., faster rates of sound identification). The mechanisms linking letter knowledge to conventional reading success operate through a combination of reduced processing resources needed to name letters and sounds and enhanced phonological and phonemic sensitivity. Over time and with more exposure, these skills will contribute to conventional reading and spelling success [11-12].

While the ANCOVA results examined whether assignment to viewing group differentiated children's literacy skills, the dose analyses evaluated just how many episodes of Super Why! it took to produce meaningful change in outcome scores. Meaningful change was defined as the number of episodes it took to increase a child's score by 1 point and to increase a child's score by a standard deviation.

On average, the maximum outcome score was achieved after viewing 20.8 episodes with diminishing gains after that point (and, in some cases, scores began to decline as children's exposure level increased). One explanation for this relation may be that children who have these skills were not interested in watching the program after a certain point while those children who did not have all of the featured skills continued to watch the program more frequently than was asked by the evaluators. To examine this possibility, correlations were computed among total exposure and parent-reported indices of child's initial reading ability. Children watched fewer episodes if, at the start of the study, they knew more alphabet letters (-0.16); knew more letter sounds (-0.24); or were better readers $(r=-0.28)$. Given these correlations, it is likely that children who watched more episodes of SW needed more exposure to evidence the same levels of change for children who had more sophisticated skills at the start.

In general, the dose analyses indicated that viewing fewer than 20 episodes was needed to produce meaningful change on the outcomes of interest. Situating these findings with those from the ANCOVA analyses indicate that Super Why! is a powerful intervention for young children. The effect sizes presented earlier further highlight that, while performance improved nearly universally for children from all levels of SES, the strength of the effects were stronger for children from low SES families.

\section{Conclusion}

Collectively, these results demonstrate that viewing Super Why! is universally beneficial as well as particularly powerful for children from low-SES homes. These children, by virtue of living in homes with fewer high quality educational materials and experiences, are at significant risk for later reading failure. Moreover, they are also likely to spend more time watching television and to report that they value the viewing experience more highly than their peers living in homes with more educational materials and experiences available. Given these documented effects on learning as well as the strong appeal of the program and its characters, Super Why! affords a unique opportunity to implement a scalable and effective intervention with little cost and much benefit to these children and their families.

Although television is often criticized for promoting intellectual passivity, these findings underscore the educational power of television particularly when a program has been developed using scientifically-based research and has been coupled with entertaining characters and formats. Super Why! is the newest addition to the arsenal of high quality, educational television programs (e.g., Sesame Street, Between the Lions, Blue's Clues) that are empirically created; scientifically evaluated; and subsequently found to help young children encode, store, retrieve, and transfer program content, in Super Why!'s case, to gains in early literacy skills 
embedded within an engaging and motivating context.

\section{References}

[1] S.M. Fisch and R.T. Truglio (Eds.), " $G$ ” is for growing: Thirty years of research on children and Sesame Street. Erlbaum, Mahwah, NJ, 2001.

[2] D.G. Singer and J.L. Singer, J.L. Handbook of Children and the Media. Sage Publications, Thousand Oaks, CA, 2001 .

[3] D. R. Anderson, "Researching Blue's Clues: Viewing behavior and impact." Media Psychology, 2 (2), pp. 179194, 2000.

[4] S.B. Neuman and K. Roskos, "The state of state prekindergarten standards." Early Childhood Research Quarterly, 20(2), pp. 125-145, 2005.

[5] K.N. Missall and S.R. McConnell, Technical Report: Psychometric characteristics of individual growth and development indicators - Picture Naming, Rhyming \& Alliteration. Minneapolis, MN: Center for Early Education and Development, 2004.

[6] M. Invernizzi, A. Sullivan and J. Meir, Phonological awareness literacy screening for preschool (PALS-PreK). Teachers' Manual. University Printing, Charlottesville, VA, 2004.

[7] B. Hart and T.R. Risley, Meaningful differences in the everyday experience of young American children. Paul $\mathrm{H}$. Brookes, Baltimore, MD, 1995.

[8] C. Juel, "Learning to read and write: A longitudinal study of 54 children from first through fourth grades." Journal of Educational Psychology, 80, pp. 437-447, 1988.

[9] K.E. Stanovich, "Matthew effects in reading: Some consequences of individual differences in the acquisition of literacy." Reading Research Quarterly, 21, pp. 360-406, 1986.
[10] D. Walker, C.R. Greenwood, B. Hart, and J. Carta, "Prediction of school outcomes based on early language production and socioeconomic factors." Child Development, 65, pp. 606-621, 1994.

[11] S.R. Burgess and C.J. Lonigan, "Bidirectional relations of phonological sensitivity and prereading abilities: Evidence from a preschool sample." Journal of Experimental Child Psychology, 70, pp. 117-141, 1988.

[12] J.N. Foulin, "Why is letter-name knowledge such a good predictor of learning to read? Reading and Writing, 18, pp. 129-155, 2005.

[13] N. Rathvon, Early Reading Assessment: A Practitioner's Handbook. Guilford, New York, NY, 2004.

[14] J. Cohen, Statistical Power Analysis for the Behavioral Sciences (2nd ed) Erlbaum, Mahwah, NJ, 1988.

\section{Acknowledgements}

The contents of this document were developed under a cooperative US Department of Education, the Corporation for Public Broadcasting, and the Public Broadcasting System for the Ready to Learn Initiative, PR\# U295A050003. However, these contents do not necessarily represent the policy of the Department of Education and you should not assume endorsement by the United States Federal Government.

Thank you to the talented and dedicated efforts of the staff and students who helped with this project. A special thank you to Katie McMenamin, Deborah K. Wainwright, and Carrie Whitworth for their hard work and dedication to all data collection efforts. In addition, thank you to the children and families that were part of this project. Without their time, energy, and enthusiasm, this project would not have been completed. 